\title{
Circulating adipocyte fatty acid-binding protein is a predictor of cardiovascular events in patients with stable angina undergoing percutaneous coronary intervention
}

Wataru Takagi ${ }^{1}$, Toru Miyoshi ${ }^{2 *}$ (D, Masayuki Doi ${ }^{1}$, Keisuke Okawa ${ }^{1}$, Kazumasa Nosaka', Tomoyuki Nishibe ${ }^{1}$, Naoaki Matsuo', Satoshi Hirohata ${ }^{3}$ and Hiroshi Ito ${ }^{2}$

\begin{abstract}
Background: Adipocyte fatty acid-binding protein (A-FABP) is expressed in both adipocytes and macrophages. Recent studies have shown that A-FABP is secreted by adipocytes and that the A-FABP concentration is associated with obesity, insulin resistance, and atherosclerosis. We have reported that the coronary atherosclerotic burden is associated with the serum A-FABP concentration. In the present study, we investigated whether the serum A-FABP concentration is associated with prognosis in patients with stable angina pectoris who have undergone percutaneous coronary intervention (PCl).
\end{abstract}

Methods: This was a prospective single-center trial. In total, 130 patients with stable angina pectoris undergoing their first PCI were enrolled from August 2008 to July 2010 at Kagawa Prefectural Central Hospital. The primary endpoints were cardiovascular death, nonfatal myocardial infarction, nonfatal stroke, revascularization, and hospitalization for heart failure.

Results: During the follow-up (median, 50 months; interquartile range, 23-66 months), 49 cardiovascular events occurred. Kaplan-Meier analysis showed that the cumulative incidence of the primary endpoints in the high AFABP group (median A-FABP concentration of $\geq 18.6 \mathrm{ng} / \mathrm{ml}$ ) was greater than that in the low A-FABP group. Cox analysis showed that the A-FABP concentration was an independent predictor of cardiovascular events adjusted for age and the presence of multi-vessel disease (hazard ratio, 1.03; 95\% confidence interval, 1.01-1.04; $p=0.01$ ).

Conclusion: The serum A-FABP concentration is associated with prognosis in patients with stable angina undergoing $\mathrm{PCl}$, suggesting that the serum A-FABP concentration could be useful for risk assessment of secondary prevention.

Trial registration: UMIN Clinical Trials Registry UMIN000029283 (registration date: September 25, 2017), retrospectively registered.

Keywords: Adipocyte, Fatty acid, Coronary artery disease, Risk factor

\footnotetext{
* Correspondence: miyoshit@cc.okayama-u.ac.jp

2Department of Cardiovascular Medicine, Okayama University Graduate

School of Medicine, Dentistry and Pharmaceutical Sciences, 2-5-1

Shikata-cho, Okayama 700-8558, Japan

Full list of author information is available at the end of the article
} 


\section{Background}

Stratification for subsequent cardiovascular events among patients with stable angina pectoris who have undergone percutaneous coronary intervention (PCI) is of considerable interest because of the potential to guide secondary preventive therapies $[1,2]$.

Adipocyte fatty acid-binding protein (A-FABP), also known as aP2 or FABP-4, is a cytoplasmic protein that is abundantly expressed in mature adipocytes and activated macrophages [3]. Substantial experimental evidence shows that A-FABP plays an important role in metabolic deterioration and the development of atherosclerosis [36]. We and other investigators previously reported that a higher circulating A-FABP concentration is an independent risk factor for coronary artery disease [7-9]. Recent studies have shown an association between the circulating A-FABP concentration and future cardiovascular disease in patients with end-stage renal disease [10], prevalent coronary heart disease [11], and acute coronary syndrome [12] as well as in a community-based cohort [13].

The aim of this study was to elucidate the association between the circulating A-FABP concentration and subsequent adverse cardiovascular events in patients with stable angina pectoris who have undergone PCI.

\section{Methods}

\section{Patients}

This was a prospective, single-center trial including patients with stable angina pectoris undergoing their first PCI. Patents' enrollment was shown in Fig. 1. Four hundred sixty-nine patients underwent PCI from August 2008 to July 2010 at Kagawa Prefectural Central
Hospital. Patients were then excluded based on the presence of any of the following criteria: acute coronary syndrome or history of PCI $(n=148)$, New York Heart Association functional classification of $\geq$ III $(n=1)$, malignant disease with an expected prognosis of $<1$ year $(n$ $=2$ ), chronic inflammatory disease $(n=1)$, and chronic renal failure (serum creatinine concentration of > $2.0 \mathrm{mg} / \mathrm{dl})(n=9)$. As patients who did not provide written informed consent $(n=3), 132$ patients consented to measurement of blood biomarkers prior to PCI. Of them, patients who had no follow-up data $(n=2)$ were also excluded. Finally, 130 patients were included in the analysis.

This study was approved by the Ethics Committee of Kagawa Prefectural Central Hospital. Written informed consent was provided by all of the patients before the study. The investigation conformed to the principles outlined in the Declaration of Helsinki.

\section{$\mathrm{PCl}$}

PCI was performed using conventional techniques by the femoral or radial approach under systemic heparinization and oral administration of aspirin and clopidogrel. The stent type and inflation pressure were chosen at the discretion of the physicians, who were blinded to the study protocol. Procedural success was defined as reduction of stenosis to $<30 \%$ of residual narrowing, improvement of ischemic symptoms, and no major in-hospital complications such as death or emergency bypass surgery. After PCI, the patients received aspirin at $100 \mathrm{mg} /$ day indefinitely and clopidogrel at $75 \mathrm{mg}$. Revascularization of the original stented target lesion was defined as repeated PCI and was performed in the presence of in-

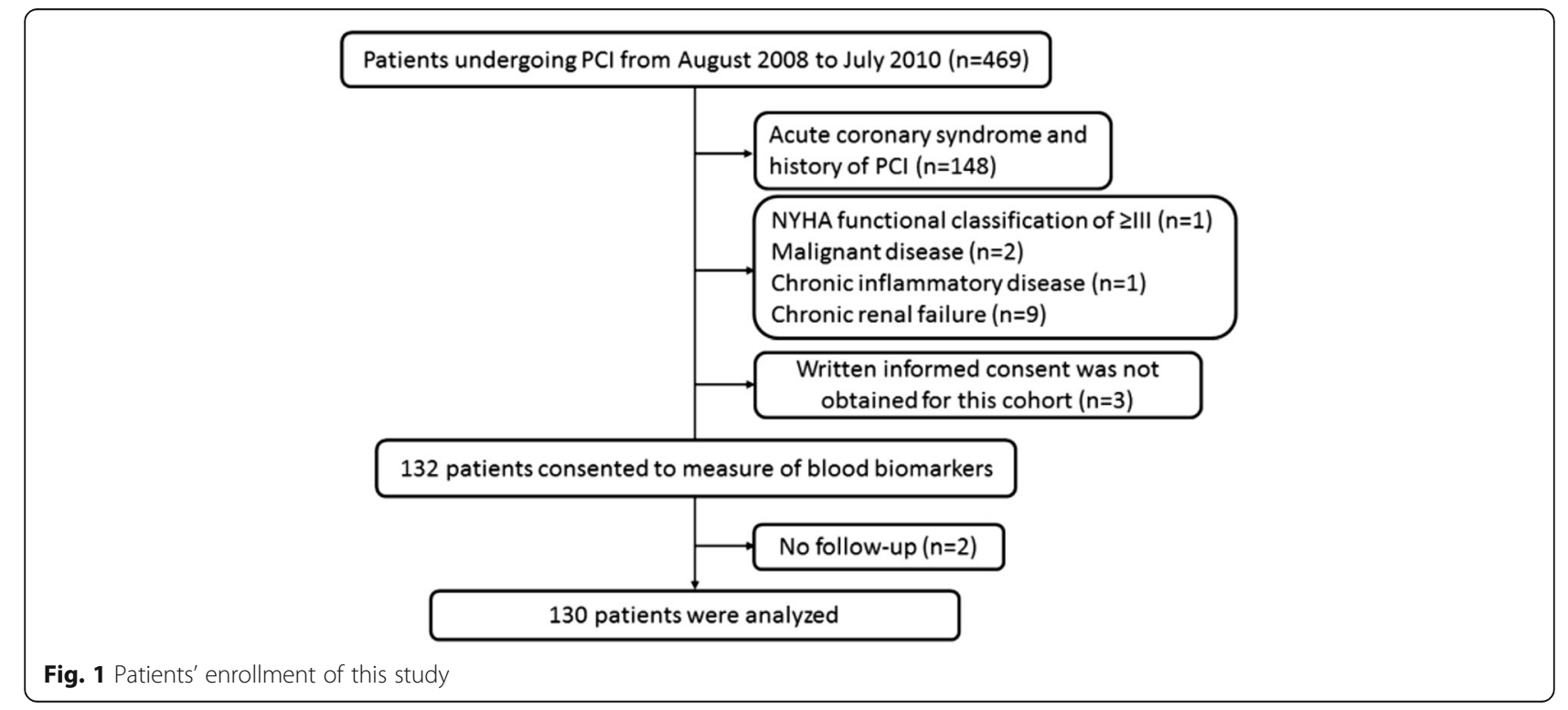


stent restenosis and any symptoms or objective signs of myocardial ischemia.

\section{Blood sampling}

Blood samples were taken after an overnight fast. The serum was separated and stored at $-80{ }^{\circ} \mathrm{C}$, and the serum concentration of A-FABP was measured by enzyme-linked immunosorbent assay (BioVendor Laboratory Medicine, Modrice, Czech Republic) [14] during follow-up. With respect to performance, this assay has a $<7 \%$ intra-assay and $<5 \%$ inter-assay coefficient of variation. Other laboratory parameters were measured using standard laboratory techniques with an automatic analyzer.

\section{Primary endpoints}

The primary endpoints were cardiovascular death, nonfatal myocardial infarction and stroke, revascularization, and hospitalization for heart failure. The time to the first primary endpoint was evaluated retrospectively. All endpoints were defined and assessed according to the statement of the American College of Cardiology/American Heart Association Task Force [15]. Myocardial infarction was defined as type 1 or 2 according to the Third Universal Definition of Myocardial Infarction [16]. Elective coronary revascularization was performed only if the invasive fractional flow reserve of a coronary lesion was $\leq 0.80$ [17]. Stroke included both ischemic and hemorrhagic types. Data were carefully collected from the clinical charts and by telephone or letter. Diagnoses was confirmed by an investigator who was blinded to the patients' data.

\section{Statistical analysis}

Continuous variables are presented as mean \pm standard deviation or median (25th, 75th percentiles), and differences between the two groups were evaluated with an unpaired $t$-test or the Mann-Whitney U-test, as appropriate. Categorical variables are presented as number (percentage), and intergroup comparisons were performed using the chi-square test. The Kaplan-Meier analysis of event-free survival during follow-up was based on the median A-FABP concentration. The association between the A-FABP concentration and future events was assessed by Cox proportional hazards analysis. Multivariate Cox proportional hazards analysis was then applied using covariates with $p$ value $<0.1$ in the univariate Cox proportional hazards analysis. Based on previous studies $[11,12]$ that reported estimated event rates of $10 \%$ and $30 \%$ in patients with low and high AFABP concentrations, respectively, a population of 144 patients would be needed to detect this difference at $\alpha=$ 0.05 and a power of 0.80 . A $p$ value of $<0.05$ was considered statistically significant. Statistical analysis was performed using SPSS 24.0 for Windows (IBM Corp., Armonk, NY).

\section{Results}

Table 1 shows the patients' baseline characteristics. The patients' age was $72 \pm 9$ years, and $81 \%$ were male. The proportions of patients with hypertension, dyslipidemia, and diabetes mellitus were $76 \%, 76 \%$, and $50 \%$, respectively. The patients were divided into two groups according to the median A-FABP concentration $(18.6 \mathrm{ng} / \mathrm{ml})$. The high A-FABP group had a higher proportion of men $(p=0.01)$ and a higher body mass index $(p<0.01)$ than the low A-FABP group. There were no significant intergroup differences in age; the presence of hypertension, dyslipidemia, diabetes mellitus, or smoking; or the parameters of lipid and glycemic control. Drug therapies, including administration of antihypertensive drugs and statins, were comparable between the low A-FABP and high A-FABP groups. The distribution of the number of diseased vessels was not significantly different between the two groups.

During the median follow-up period of 50 months (interquartile range, 23-66 months), we confirmed 49 cardiovascular events (18 in the low A-FABP group and 31 in the high A-FABP group), including 16 cardiovascular deaths (5 in the low A-FABP group and 11 in the high A-FABP group), 6 strokes (4 in the low A-FABP group and 2 in the high A-FABP group), 18 revascularizations (7 in the low A-FABP group and 11 in the high A-FABP group), and 9 hospitalizations for heart failure ( 2 in the low A-FABP group and 9 in the high A-FABP group). The follow-up durations in the low and high AFABP groups did not differ significantly (median [interquartile range]: 50 months [36-75 months] and 48 months [18-66 months], respectively; $p=0.54$ ). As shown in Table 2, the estimated total event rate in the high A-FABP group was significantly greater at 1 year than that in the low A-FABP group. Kaplan-Meier survival curves showed that the high A-FABP group had a significantly higher mortality rate than the low A-FABP group (Fig. 2). The Cox proportional hazard regression analysis to predict cardiovascular events included AFABP concentration, age, men, hypertension, diabetes mellitus, dyslipidemia, smoking, multi-vessel disease, and medications (Table 3). The model demonstrated that the A-FABP concentration was a significant explanatory variable after adjustment for the other parameters, suggesting that a higher A-FABP level is an independent predictor of long-term cardiovascular events (hazard ratio, 1.03; 95\% confidence interval, 1.01-1.04; $p=0.01$ ).

\section{Discussion}

We found that the circulating A-FABP concentration predicts cardiovascular events in patients with stable angina undergoing PCI. Further analysis using a multivariableadjusted model supported the presence of an independent association between the A-FABP concentration and 
Table 1 Patients' characteristics

\begin{tabular}{|c|c|c|c|c|}
\hline & All $(n=130)$ & $\begin{array}{l}\text { low A-FABP }<18.6 \mathrm{ng} / \mathrm{ml} \\
(n=65)\end{array}$ & $\begin{array}{l}\text { high A-FABP } \geq 18.6 \mathrm{ng} / \mathrm{ml} \\
(n=65)\end{array}$ & $p$ value (high vs. low) \\
\hline A-FABP $(\mathrm{ng} / \mathrm{ml})$ & $18.6(13.8,27.3)$ & $14.2(11.2,16.8)$ & $25.6(22.6,34.7)$ & \\
\hline Age (years) & $72 \pm 9$ & $72 \pm 9$ & $71 \pm 9$ & 0.77 \\
\hline Men, n (\%) & $105(81)$ & $47(72)$ & $89(81)$ & 0.01 \\
\hline Body mass index $\left(\mathrm{kg} / \mathrm{m}^{2}\right)$ & $24.5 \pm 3.3$ & $23.6 \pm 2.8$ & $25.4 \pm 3.5$ & $<0.01$ \\
\hline Hypertension, n (\%) & $99(76)$ & $51(78)$ & $48(74)$ & 0.54 \\
\hline Dyslipidemia, n (\%) & $99(76)$ & $50(77)$ & $49(75)$ & 0.42 \\
\hline Diabetes mellitus, n (\%) & $65(50)$ & $33(51)$ & $32(49)$ & 0.51 \\
\hline Smoking, n (\%) & $18(14)$ & $9(14)$ & $9(14)$ & 0.99 \\
\hline LDL cholesterol (mg/dl) & $103 \pm 28$ & $104 \pm 25$ & $102 \pm 31$ & 0.64 \\
\hline HDL cholesterol (mg/dl) & $43 \pm 11$ & $41 \pm 10$ & $44 \pm 12$ & 0.13 \\
\hline Triglycerides (mg/dl) & $141(102,181)$ & $132(97,187)$ & $148(118,178)$ & 0.57 \\
\hline Fasting blood sugar (mg/dl) & $99(92,119)$ & $99(92,119)$ & $100(92,120)$ & 0.82 \\
\hline Serum creatinine (mg/l) & $0.85(0.70,1.00)$ & $0.86(0.70,0.96)$ & $0.82(0.71,1.01)$ & 0.35 \\
\hline HemoglobinA1c (\%) & $5.8(5.3,6.7)$ & $5.6(5.2,6.6)$ & $5.9(5.3,6.8)$ & 0.34 \\
\hline hsCRP (mg/l) & $0.14(0.04,0.36)$ & $0.11(0.04,0.34)$ & $0.16(0.06,0.41)$ & 0.56 \\
\hline \multicolumn{5}{|l|}{ Number of diseased vessels } \\
\hline One & $56(43)$ & $32(49)$ & $24(37)$ & \\
\hline Two & $42(32)$ & $21(33)$ & $21(32)$ & 0.21 \\
\hline Three & $32(25)$ & $12(18)$ & $20(31)$ & \\
\hline \multicolumn{5}{|l|}{ Medications } \\
\hline Antiplatelets & $130(100)$ & $65(100)$ & $65(100)$ & 1.00 \\
\hline ACEIs/ARBs & $70(54)$ & $35(54)$ & $35(54)$ & 0.99 \\
\hline Calcium channel blockers & $64(49)$ & $33(51)$ & $31(48)$ & 0.75 \\
\hline$\beta$-blockers & $39(30)$ & $16(25)$ & $23(35)$ & 0.18 \\
\hline Statins & $75(58)$ & $40(62)$ & $35(54)$ & 0.32 \\
\hline
\end{tabular}

Data are expressed as mean \pm standard deviation, or number (\%), or median (25th, 75th percentiles)

$L D L$ low-density lipoprotein, $H D L$ high-density lipoprotein, $A-F A B P$ adipocyte fatty acid-binding protein, hsCRP high-sensitivity $C$-reactive protein, $A C E I$ angiotensinconverting enzyme inhibitor; $A R B$, angiotensin II receptor blocker

subsequent cardiovascular events. To our knowledge, this is the first long-term prospective study to demonstrate that the circulating A-FABP concentration is linked to clinical cardiovascular outcomes in patients with stable angina undergoing PCI.

Several studies have evaluated the association between the circulating A-FABP concentration and future cardiovascular events. Chow et al. reported that the circulating A-FABP concentration predicted the development of cardiovascular disease in a community-based cohort [13]. Eynatten et al. identified an association between the circulating A-FABP concentration and long-term prognosis in patients with coronary heart disease [11]. In their study, many participants were patients with an old myocardial infarction undergoing coronary artery bypass grafting, $\mathrm{PCI}$, and noninvasive treatment. Other groups reported the usefulness of the circulating A-FABP concentration as a prognostic biomarker in patients with acute coronary syndrome as well as in those with end-stage renal disease
$[12,10]$. Our study included patients with stable angina pectoris who underwent PCI, which is an advantage in terms of understanding the clinical relevance of the circulating A-FABP concentration in this specific population.

The present study showed that women had higher AFABP concentrations than men. Sex-related differences in the circulating A-FABP concentration have been reported in several previous studies $[8,14]$. The expression of A-FABP in subcutaneous adipose was higher than that in visceral adipose tissue [18]. Men generally have more visceral fat, and women have more subcutaneous fat. Furthermore, the A-FABP concentration has been shown to be negatively correlated with the free testosterone concentration in women [19], suggesting that testosterone suppresses the expression of A-FAPB. The differences in the regional fat distribution and sex hormones may explain the sex-related difference.

The underlying mechanisms involved in the association between the circulating A-FABP concentration and 
Table 2 Primary endpoints at 1 and 3 years

\begin{tabular}{|c|c|c|c|}
\hline & low A-FABP & high A-FABP & $p$ value $^{\mathrm{a}}$ (high vs. low) \\
\hline \multicolumn{4}{|l|}{ At 1 year } \\
\hline Total events & $4(6 \%)$ & $15(23 \%)$ & 0.006 \\
\hline Cardiovascular death & $0(0 \%)$ & $4(7 \%)$ & 0.035 \\
\hline Nonfatal myocardial infarction & $0(0 \%)$ & $0(0 \%)$ & N/A \\
\hline Nonfatal stroke & $0(0 \%)$ & $1(1 \%)$ & 0.317 \\
\hline Revascularization & $2(3 \%)$ & $7(12 \%)$ & 0.063 \\
\hline Hospitalization for heart failure & $2(3 \%)$ & $3(5 \%)$ & 0.596 \\
\hline \multicolumn{4}{|l|}{ At 3 years } \\
\hline Total events & $15(23 \%)$ & $23(35 \%)$ & 0.084 \\
\hline Cardiovascular death & $4(7 \%)$ & $7(13 \%)$ & 0.249 \\
\hline \multicolumn{4}{|l|}{ Nonfatal myocardial infarction } \\
\hline Nonfatal stroke & $3(5 \%)$ & $2(4 \%)$ & 0.765 \\
\hline Revascularization & $6(10 \%)$ & $9(15 \%)$ & 0.288 \\
\hline Hospitalization for heart failure & $2(3 \%)$ & $5(9 \%)$ & 0.204 \\
\hline
\end{tabular}

Data are expressed as number and Kaplan-Meier estimated event rates at 1 year and 3 years

a Log-rank test was performed for comparison between two groups

$A-F A B P$ adipocyte fatty acid-binding protein

future cardiovascular events remain unclear. However, there are several potential explanations. First, A-FABP derived from adipose tissue or activated macrophages may directly influence the vasculature. Previous experimental studies have shown that A-FABP induces smooth muscle cell proliferation and inhibits the expression/activation of endothelial nitric oxide synthase in vascular endothelial cells $[20,21]$. Another study showed that AFABP locally produced by perivascular fat and macrophages in vascular plaques contributes to the development

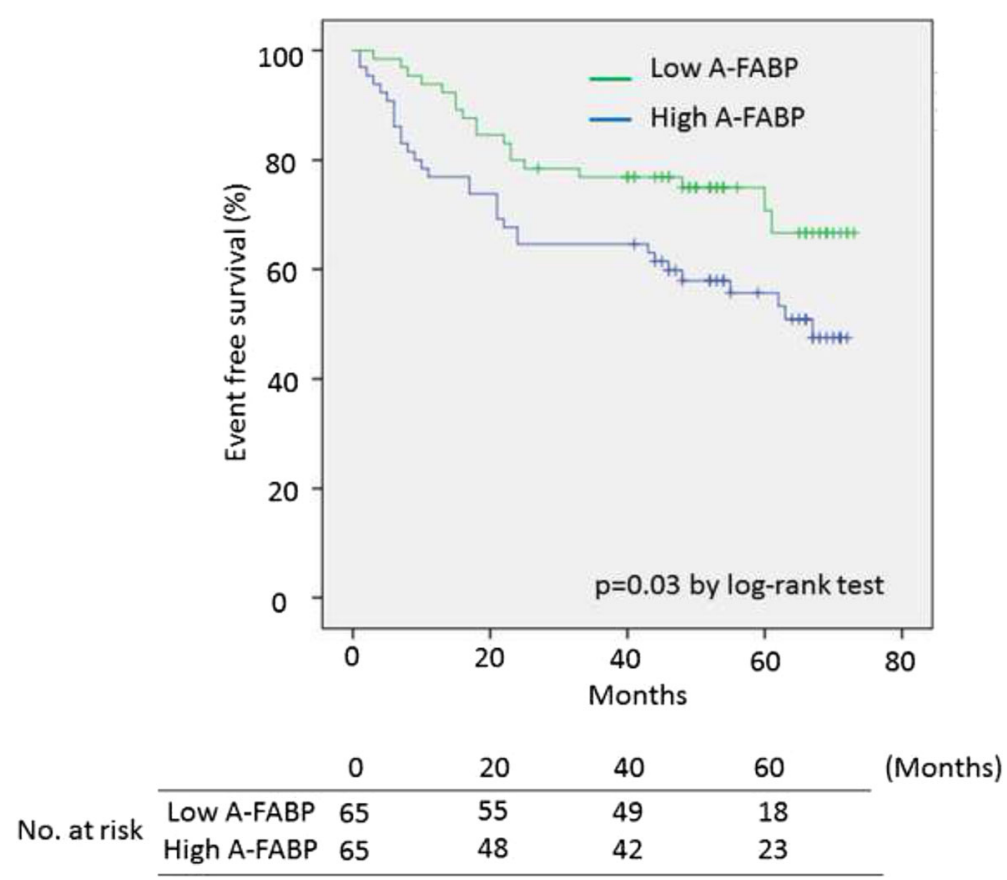

Fig. 2 Kaplan-Meier curves for the primary outcomes. Shown are the cumulative event-free rates for the primary endpoint of death from cardiovascular disease, nonfatal myocardial infarction, nonfatal stroke, revascularization, and hospitalization for heart failure (beginning from the time of percutaneous coronary intervention to the day of the first occurrence of a primary endpoint event, the day of the last office or phone visit, or the day of death during follow-up) 
Table 3 Multivariate analysis

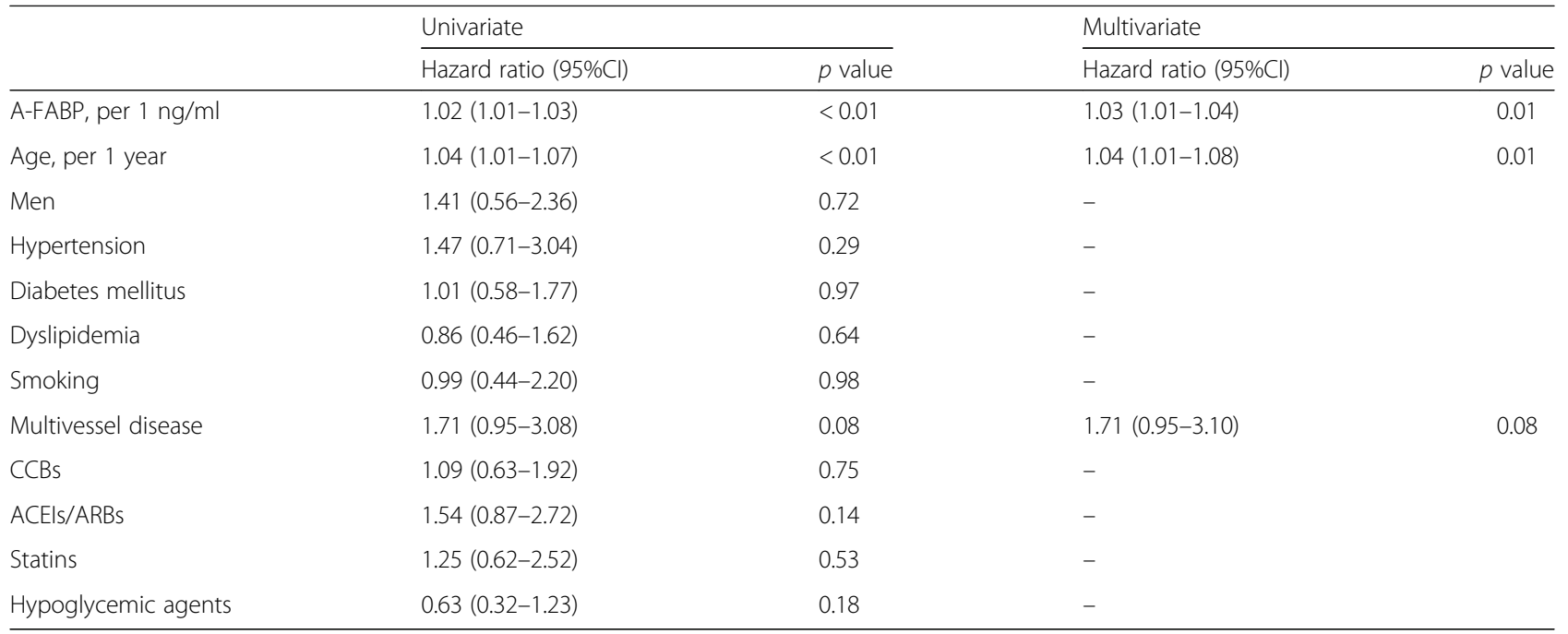

$C /$ confidence interval, $A-F A B P$ adipocyte fatty acid-binding protein, $C C B s$ calcium channel blockers, $A C E l$ angiotensin-converting enzyme inhibitor, $A R B$ angiotensin II receptor blocker. Multivariate Cox proportional hazards analysis was then applied using covariates with $\mathrm{p}$ value $<0.1$ in the univariate Cox proportional hazards analysis

of coronary atherosclerosis [22]. Second, the presence of a high circulating A-FABP concentration is a consequence of accumulation of cardiometabolic risks. Our clinical studies showed that the A-FABP concentration is associated with the body mass index; concentrations of triglycerides, high-density lipoprotein cholesterol, adiponectin, and C-reactive protein; and the homeostasis model assessment-insulin resistance value $[8,14,23-25]$. Thus, the circulating A-FABP concentration is closely associated with obesity, insulin resistance, and type 2 diabetes. However, in the present study, the multivariate analysis revealed that the circulating A-FABP concentration was an independent factor associated with future cardiovascular events. In addition, a genotype-phenotype study showed that carriers of the T-87C polymorphism at the A-FABP locus have a reduced risk for coronary heart disease [26]. Basically, A-FABP works as a chaperon of fatty acids in cells. Thus, interaction of A-FABP and its modulation of cardiovascular risk factors may be another explanation.

We demonstrated the usefulness of the baseline circulating A-FABP concentration as a predictor of future cardiovascular events. Meanwhile, the circulating AFABP concentration can be modified. We previously reported that an angiotensin II receptor blocker reduced the serum A-FABP concentration in hypertensive patients [23]. Other groups showed that the A-FABP concentration decreased by an omega-3 fatty acid [27], a statin [28], and a dipeptidyl peptidase 4 inhibitor [29] and possibly increased by a sodium-glucose cotransporter 2 inhibitor [30]. Experimental studies have identified several compounds that directly block A-FABP [31-33], but no clinical applications are available. The impact of changes in the circulating A-FABP concentration on cardiovascular events remains unknown. Further studies are required to evaluate the direct impact of changes in the circulating A-FABP concentration on clinical outcomes.

\section{Limitations}

This study has several limitations. First, a small number of patients were enrolled. Second, we included only Japanese patients with stable angina undergoing PCI; therefore, our findings cannot be extrapolated to other ethnic groups or patients without cardiovascular disease. In addition, we excluded patients with acute coronary syndrome, history of PCI, a New York Heart Association functional classification of $\geq$ III, malignant disease with an expected prognosis of $<1$ year, chronic inflammatory disease, and chronic renal failure (serum creatinine concentration of $>2.0 \mathrm{mg} / \mathrm{dl}$ ). Our findings cannot be applied to all patients with stable angina pectoris undergoing PCI. The results must therefore be interpreted with caution. Third, most of the differences between the two groups occurred in the "soft" endpoints of revascularization and hospitalization for heart failure. Thus, it is possible that A-FABP is more closely associated with symptoms or other laboratory results that would result in more intense treatment approaches rather than disease progression itself. Fourth, our study design precluded the investigation of a direct causal relationship. To determine this causal relationship, long-term interventional studies involving therapeutic agents that reduce A-FABP expression or action such as A-FABP inhibitors are warranted. 


\section{Conclusions}

The circulating A-FABP concentration is a predictor of subsequent cardiovascular events in patients with stable angina who have undergone PCI. This finding suggests that the circulating A-FABP concentration has the potential to guide secondary preventive therapies.

\section{Abbreviations}

A-FABP: Adipocyte fatty acid-binding protein; PCl: Percutaneous coronary intervention

\section{Acknowledgements}

We are grateful to Michiyo Ishikawa for her scientific input, discussion, and contributions.

\section{Funding}

This work was supported by JSPS KAKENHI Grant Number 15 K09157.

\section{Availability of data and materials}

All data and material are available from the corresponding author on reasonable request.

\section{Authors' contributions}

WT, TM, MD, KO, KN, TN, NM, SH, HI each made substantial contributions to conception and design, or acquisition of data, or analysis and interpretation of data; was involved in drafting the manuscript or revising it critically for important intellectual content. All authors had read and approved the final manuscript.

\section{Ethics approval and consent to participate}

The study was approved by the Ethics Committee of Kagawa Prefectural Hospital (1-2-1 Asahimachi, Takamatsu City, Kagawa Prefecture, Japan, 760 8557). All participants provided written informed consent before enrollment. This study was conducted according to the principles expressed in the Declaration of Helsink

\section{Consent for publication}

Not applicable.

\section{Competing interests}

The authors declare that they have no competing interests.

\section{Publisher's Note}

Springer Nature remains neutral with regard to jurisdictional claims in published maps and institutional affiliations.

\section{Author details}

Department of Cardiology, Kagawa Prefectural Central Hospital, Takamatsu, Japan. ${ }^{2}$ Department of Cardiovascular Medicine, Okayama University Graduate School of Medicine, Dentistry and Pharmaceutical Sciences, 2-5-1 Shikata-cho, Okayama 700-8558, Japan. ${ }^{3}$ Department of Medical Technology, Okayama University Graduate School of Health, Okayama, Japan.

Received: 14 December 2016 Accepted: 3 October 2017 Published online: 10 October 2017

\section{References}

1. Fihn SD, Gardin JM, Abrams J, Berra K, Blankenship JC, Dallas AP, et al. ACCF/AHA/ACP/AATS/PCNA/SCAI/STS Guideline for the diagnosis and management of patients with stable ischemic heart disease: a report of the American College of Cardiology Foundation/American Heart Association Task Force on Practice Guidelines, and the American College of Physicians, American Association for Thoracic Surgery, Preventive Cardiovascular Nurses Association, Society for Cardiovascular Angiography and Interventions, and Society of Thoracic Surgeons. J AM Coll Cardiol. 2012;60(24):e44-e164.

2. Yusuf S, Rangarajan S, Teo K, Islam S, Li W, Liu L, et al. Cardiovascular risk and events in 17 low-, middle-, and high-income countries. N Engl J Med. 2014;371(9):818-27.
3. Hotamisligil GS, Johnson RS, Distel RJ, Ellis R, Papaioannou VE, Spiegelman BM. Uncoupling of obesity from insulin resistance through a targeted mutation in aP2, the adipocyte fatty acid binding protein. Science. 1996;274(5291):1377-9.

4. Gold C. A primary mesothelioma involving the rectovaginal septum and associated with beryllium. J Pathol Bacteriol. 1967;93(2):435-42.

5. Boord JB, Maeda K, Makowski L, Babaev VR, Fazio S, Linton MF, et al. Adipocyte fatty acid-binding protein, aP2, alters late atherosclerotic lesion formation in severe hypercholesterolemia. Arterioscler Thromb Vasc Biol. 2002;22(10):1686-91.

6. Makowski L, Boord JB, Maeda K, Babaev VR, Uysal KT, Morgan MA, et al. Lack of macrophage fatty-acid-binding protein aP2 protects mice deficient in apolipoprotein E against atherosclerosis. Nat Med. 2001;7(6):699-705.

7. Bao Y, Lu Z, Zhou M, Li H, Wang Y, Gao M, et al. Serum levels of adipocyte fatty acid-binding protein are associated with the severity of coronary artery disease in Chinese women. PLoS One. 2011;6(4):e19115.

8. Doi M, Miyoshi T, Hirohata S, Nakamura K, Usui S, Takeda K, et al. Association of increased plasma adipocyte fatty acid-binding protein with coronary artery disease in non-elderly men. Cardiovasc Diabetol. 2011;10:44.

9. Rhee EJ, Lee WY, Park CY, KW O, Kim BJ, Sung KC, et al. The association of serum adipocyte fatty acid-binding protein with coronary artery disease in Korean adults. Eur J Endocrinol. 2009;160(2):165-72.

10. Furuhashi M, Ishimura $\mathrm{S}, \mathrm{Ota} \mathrm{H}$, Hayashi M, Nishitani T, Tanaka M, et al. Serum fatty acid-binding protein 4 is a predictor of cardiovascular events in end-stage renal disease. PLoS One. 2011;6(11):e27356.

11. von Eynatten $M$, Breitling LP, Roos $M$, Baumann $M$, Rothenbacher $D$, Brenner $H$. Circulating adipocyte fatty acid-binding protein levels and cardiovascular morbidity and mortality in patients with coronary heart disease: a 10-year prospective study. Arterioscler Thromb Vasc Biol. 2012;32(9):2327-35.

12. Reiser $H$, Klingenberg $R$, Hof D, Cooksley-Decasper S, Fuchs N, Akhmedov A et al. Circulating FABP4 is a prognostic biomarker in patients with acute coronary syndrome but not in asymptomatic individuals. Arterioscler Thromb Vasc Biol. 2015;35(8):1872-9.

13. Chow WS, Tso AW, Xu A, Yuen MM, Fong CH, Lam TH, et al. Elevated circulating adipocyte-fatty acid binding protein levels predict incident cardiovascular events in a community-based cohort: a 12-year prospective study. J Am Heart Assoc. 2013;2(1):e004176.

14. Miyoshi T, Onoue G, Hirohata A, Hirohata S, Usui S, Hina K, et al. Serum adipocyte fatty acid-binding protein is independently associated with coronary atherosclerotic burden measured by intravascular ultrasound. Atherosclerosis. 2010;211(1):164-9.

15. Hicks KA, Tcheng JE, Bozkurt B, Chaitman BR, Cutlip DE, Farb A et al:: 2014 ACC/AHA Key Data Elements and Definitions for Cardiovascular Endpoint Events in Clinical Trials: A Report of the American College of Cardiology/ American Heart Association Task Force on Clinical Data Standards (Writing Committee to Develop Cardiovascular Endpoints Data Standards). Circulation 2015, 132(4):302-361.

16. Thygesen K, Alpert JS, Jaffe AS, Simoons ML, Chaitman BR, White HD, et al. Third universal definition of myocardial infarction. Circulation. 2012;126(16):2020-35.

17. Tonino PA, De Bruyne B, Pijls NH, Siebert U, Ikeno F, Van't Veer M, et al. Fractional flow reserve versus angiography for guiding percutaneous coronary intervention. N Engl J Med. 2009;360(3):213-24.

18. Fisher RM, Eriksson P, Hoffstedt J, Hotamisligil GS, Thorne A, Ryden M, et al. Fatty acid binding protein expression in different adipose tissue depots from lean and obese individuals. Diabetologia. 2001:44(10):1268-73.

19. Doganay M, Ozyer SS, Var T, Tonguc E, Gun Eryilmaz O, Ozer I, et al. Associations between adipocyte fatty acid-binding protein and clinical parameters in polycystic ovary syndrome. Arch Gynecol Obstet. 2015;291(2):447-50.

20. Aragones G, Saavedra P, Heras M, Cabre A, Girona J, Masana L. Fatty acidbinding protein 4 impairs the insulin-dependent nitric oxide pathway in vascular endothelial cells. Cardiovasc Diabetol. 2012;11:72.

21. Girona J, Rosales R, Plana N, Saavedra P, Masana L, Vallve JC. FABP4 induces vascular smooth muscle cell proliferation and migration through a MAPKdependent pathway. PLoS One. 2013;8(11):e81914

22. Furuhashi M, Fuseya T, Murata M, Hoshina K, Ishimura S, Mita T, et al. Local Production of Fatty Acid-Binding Protein 4 in Epicardial/Perivascular Fat and Macrophages Is Linked to Coronary Atherosclerosis. Arterioscler Thromb Vasc Biol. 2016:36(5):825-34.

23. Miyoshi T, Doi M, Hirohata S, Kamikawa S, Usui S, Ogawa H, et al. Olmesartan reduces arterial stiffness and serum adipocyte fatty acid-binding protein in hypertensive patients. Heart Vessel. 2011;26(4):408-13. 
24. Kajiya M, Miyoshi T, Doi M, Usui S, Iwamoto M, Takeda K, et al. Serum adipocyte fatty acid-binding protein is independently associated with complex coronary lesions in patients with stable coronary artery disease. Heart Vessel. 2013;28(6):696-703.

25. Iwamoto M, Miyoshi T, Doi M, Takeda K, Kajiya M, Nosaka K, et al. Elevated serum adipocyte fatty acid-binding protein concentrations are independently associated with renal dysfunction in patients with stable angina pectoris. Cardiovasc Diabetol. 2012;11:26.

26. Tuncman G, Erbay E, Hom X, De Vivo I, Campos H, Rimm EB, et al. A genetic variant at the fatty acid-binding protein aP2 locus reduces the risk for hypertriglyceridemia, type 2 diabetes, and cardiovascular disease. Proc Nat Acad Sci U S A. 2006;103(18):6970-5.

27. Furuhashi M, Hiramitsu S, Mita T, Omori A, Fuseya T, Ishimura S, et al. Reduction of circulating FABP4 level by treatment with omega-3 fatty acid ethyl esters. Lipids Health Dis. 2016;15:5

28. Karpisek M, Stejskal D, Kotolova H, Kollar P, Janoutova G, Ochmanova R, et al. Treatment with atorvastatin reduces serum adipocyte-fatty acid binding protein value in patients with hyperlipidaemia. Eur J Clin Investig. 2007;37(8): 637-42.

29. Furuhashi M, Hiramitsu S, Mita T, Fuseya T, Ishimura S, Omori A, et al. Reduction of serum FABP4 level by sitagliptin, a DPP-4 inhibitor, in patients with type 2 diabetes mellitus. J Lipid Res. 2015:56(12):2372-80.

30. Furuhashi M, Matsumoto M, Hiramitsu S, Omori A, Tanaka M, Moniwa N, et al Possible Increase in Serum FABP4 Level Despite Adiposity Reduction by Canagliflozin, an SGLT2 Inhibitor. PLoS One. 2016;11(4):e0154482.

31. Furuhashi M, Tuncman G, Gorgun CZ, Makowski L, Atsumi G, Vaillancourt E, et al. Treatment of diabetes and atherosclerosis by inhibiting fatty-acidbinding protein aP2. Nature. 2007:447(7147):959-65.

32. Wang Y, Lin HQ, Law WK, Liang WC, Zhang JF, Hu JS, et al. Pimozide, a novel fatty acid binding protein 4 inhibitor, promotes adipogenesis of 3T3L1 cells by activating PPARgamma. ACS Chem Neurosci. 2015;6(2):211-8.

33. Cai H, Liu Q, Gao D, Wang T, Chen T, Yan G, et al. Novel fatty acid binding protein 4 (FABP4) inhibitors: virtual screening, synthesis and crystal structure determination. Eur J Med Chem. 2015;90:241-50

\section{Submit your next manuscript to BioMed Central and we will help you at every step:}

- We accept pre-submission inquiries

- Our selector tool helps you to find the most relevant journal

- We provide round the clock customer support

- Convenient online submission

- Thorough peer review

- Inclusion in PubMed and all major indexing services

- Maximum visibility for your research

Submit your manuscript at www.biomedcentral.com/submit 